\title{
Research on the Numerical Calculation Method for Antiloosening Performance of Screwed Joints under Complex Working Conditions
}

\author{
Yimin Mo, ${ }^{1}$ Shenghui Guo ${ }^{D},{ }^{1}$ Xiongzhen Qin, ${ }^{2}$ Jialiang Qin, ${ }^{2}$ Kui Zhan, \\ and Xinshang Gao \\ ${ }^{1}$ School of Mechanical and Electronic Engineering, Wuhan University of Technology, Wuhan 430070, China \\ ${ }^{2}$ SAIC-GM-Wuling Automobile Co., Ltd., Liuzhou 545007, China \\ Correspondence should be addressed to Shenghui Guo; shenghui.guo@whut.edu.cn
}

Received 7 December 2019; Revised 18 March 2020; Accepted 22 April 2020; Published 12 May 2020

Academic Editor: Roberto G. Citarella

Copyright (c) 2020 Yimin Mo et al. This is an open access article distributed under the Creative Commons Attribution License, which permits unrestricted use, distribution, and reproduction in any medium, provided the original work is properly cited.

\begin{abstract}
This study aimed at addressing the difficulties entailed in accurately determining the working loads of screwed joints (SJs) by establishing mechanical models and verifying the accuracy of the numerical calculation model of antiloosening performance under complex working conditions. First, considering the slip state of the interface and the stress state of the thread surface, a corresponding mechanical model was established to investigate the quantitative model of the interaction amongst structural parameters, complex working loads, and antiloosening performance of SJs. The applicability of existing models is expanded by this new model. Second, a load calibration test, an actual working condition test, and a dynamic simulation were combined to accurately determine the load under complex working conditions. A new experimental scheme for measuring the critical residual preload was employed to verify the reliability and accuracy of the numerical calculation model. The results confirmed that structural safety is ensured and that accident risk is reduced. Finally, based on this model, the transverse load, axial load, bending moment, torque about the bolt axis, clamping eccentricity, loading eccentricity, and coefficient of friction in the thread and at the interface were analyzed in terms of the antiloosening performance. The results of this study are expected to provide significant guidance to engineering practices. Moreover, the numerical calculation model can accurately predict the antiloosening performance and failure and also provide technical support for improving the structural reliability, particularly for key screwed-joint structures (SJSs), under complex working conditions loading.
\end{abstract}

\section{Introduction}

Screwed joints (SJs) are widely used in various mechanical structures owing to their advantages of having a simple structure, easy assembly or disassembly and adjustment, and so on. Screwed-joint performances (SJPs) are important for obtaining the overall structural characteristics and estimating the probability of the main cause for structural damage and failure. Screwed-joint structures (SJSs) typically undergo loosening failure during service, which may lead to product failure or major accidents. The loss of preload, which is directly linked to loosening, is affected by external loads and structural parameters [1-6]. The external loads break the original force balance at the SJS, and the preload reduction at the SJS is caused by plastic deformation and slipping. The structural parameters and preload exert significant influence on the distribution and transmission of external loads.

In engineering practice, different structural parameters (shape, size, material properties, clamping eccentricity, loading eccentricity, coefficient of friction in the thread and at the interface, and so on) and loads (preload, transverse load, axial load, bending moment, torque about the bolt axis, and so on) are considered under complex working conditions. The study of the interaction between the loads and the structural parameters is complex because the loosening of SJSs is also a complicated process. In studies investigating the influence of loads and parameters 
on loosening to establish a simple and effective numerical model and accurately predict the antiloosening performance and failure, the following challenges have been encountered: (1) owing to the complexity of the working conditions and loads, the occurrence of substantial error affects the load measurement by instruments and equipment and makes it difficult to accurately obtain the load values; (2) the consideration of complex working loads, slip state of the interface, stress state of the thread surface, influences of eccentric clamping and eccentric loading on the loads, elastic resilience, and load coefficient make it difficult to establish the mechanical models of SJs; (3) the complexity of working loads and the difficulty of measuring the antiloosening performance complicate the process of constructing a test method for verifying the accuracy of the numerical calculation model.

Research on the loosening problems of SJs has been conducted since the 1940s [1]. Goodier and Sweeney [2] proposed the theory and model for the occurrence of loosening during the dynamic loading of SJs and thus contributed toward understanding the parameters related to loosening, such as the bolt diameter and thread pitch. Clark and Cook [3] investigated the effect of fluctuating torque on the loosening of a tightly seated bolt. Until then, researchers had focused on the loosening caused by axial loads. In contrast, Junker [4] experimentally determined that the transverse loads result in greater risk than the axial loads, and his test apparatus for assessing the loosening according to the vibration, called the "Junker test machine," has been widely used. However, because this test machine can only apply transverse loading to bolts, it cannot be used for simulation and failure prediction in engineering practice. Finkelston [5] investigated the relationship between the selfloosening of bolted joints and influencing parameters such as vibration amplitude, initial preload, thread pitch, and surface characteristics. However, he did not investigate the interactions amongst these factors. Moreover, the VDI-2230 standard [6] ensures a satisfactory antiloosening performance of the structure by calculating the safety margin against interface slipping during the design of SJSs. The limit value of the safety margin is determined by the user. Gong and Liu developed a three-dimensional finite element model to investigate the effects of the preload generation, vibration parameter, and material model on the loosening [7] and identified the critical transverse force for initiating loosening [8]. Zhao et al. [9] proposed a simplified numerical model of bolt slipping for simulating SJs and better capturing the slipping phenomenon. Zhu et al. developed a high-precision instrument to determine the effect of variables on the initial loss of preload [10] and proposed a torque-preload force formula for evaluating the antiloosening performance of thread fasteners [11]. Jiang et al. [12-14] found that the external lateral load has a critical value. When the load is lower than the critical value, the bolt does not loosen. Pai and Hess [15] pointed out that the overall slippage of the bearing surface under the screw head is a necessary condition for the loosening by rotation of the bolt and nut. In the literature [16-18], it is reported that, under the repeated action of a transverse load, the local slip of the bearing surface and the thread surface under the screw head gradually accumulate elastic strain energy at the contact surface. When energy is accumulated to a certain extent, the entire contact surface exhibits slippage, which leads to bolt loosening. Dinger [19] employed the critical loosening gradient of a screw head $(0.01 \%$ cycle $)$ to evaluate the loosening of a bolted joint. Izumi et al. investigated the mechanisms of loosening caused by microbearing-surface slippage under transverse loading within the framework of the three-dimensional finite element method [20] and found that the loosening commenced when the thread surface exhibited complete slippage, regardless of the slip status of the bearing surface [21]. Gong et al. [22] analyzed local slippage accumulation on the bearing surface using the modified Iwan's model and developed a thorough understanding of the loosening mechanism. Various theoretical models [23-33] have been proposed to understand the mechanism of loosening caused by complete slippage under transversal vibration. Yokoyama et al. [34] investigated the loosening of bolted joints subjected to cyclic torqueing.

In summary, existing studies have mainly investigated the influence of the SJS parameters on antiloosening performance under simple working conditions loading. However, the exact quantitative relationship amongst the structural parameters, complex working loads, and loosening has not yet been obtained. Moreover, VDI-2230 [6] provides a method for calculating the safety margin against interface slippage, whose limit value is determined according to experience or by the users to prevent the interface slippage and bolt/nut loosening by rotation. However, the mechanism of loosening by rotation under complex working conditions is not fully considered; thus, the limit value of the safety margin cannot be accurately determined. Other studies have mainly investigated the influence of a single transverse load or torque on the preload loss, interface slippage, or bolt/nut loosening by rotation. However, in engineering practice, the structural parameters and loads on the SJSs are complex, and the results obtained by existing studies do not accurately predict the antiloosening performance and loosening failure. Therefore, in the design process, it is necessary to comprehensively consider the intrinsic relationship amongst the structural parameters, complex working loads, and antiloosening performance.

In this study, an investigation and a verification scheme for the numerical calculation model of antiloosening performance under complex working conditions loading were constructed, as shown in Figure 1. The following process was employed: (1) load data (Figure 1(e)) were obtained by conducting load calibration tests (Figure 1(b)) and tests under actual working conditions (Figure 1(c)) to calibrate the dynamics simulation model (Figure 1(a)); thereafter, the typical, complex working conditions were simulated, and the load data (Figure 1(f)) of the SJSs were output. (2) The mechanical model of the SJSs was established by considering the clamped parts and fastener model (Figure 1(d)), complex working loads, eccentric clamping, and eccentric loading (Figure 1(h)). Based on the slip state of the interface of clamped parts, criteria for determining the interface slip were established, 


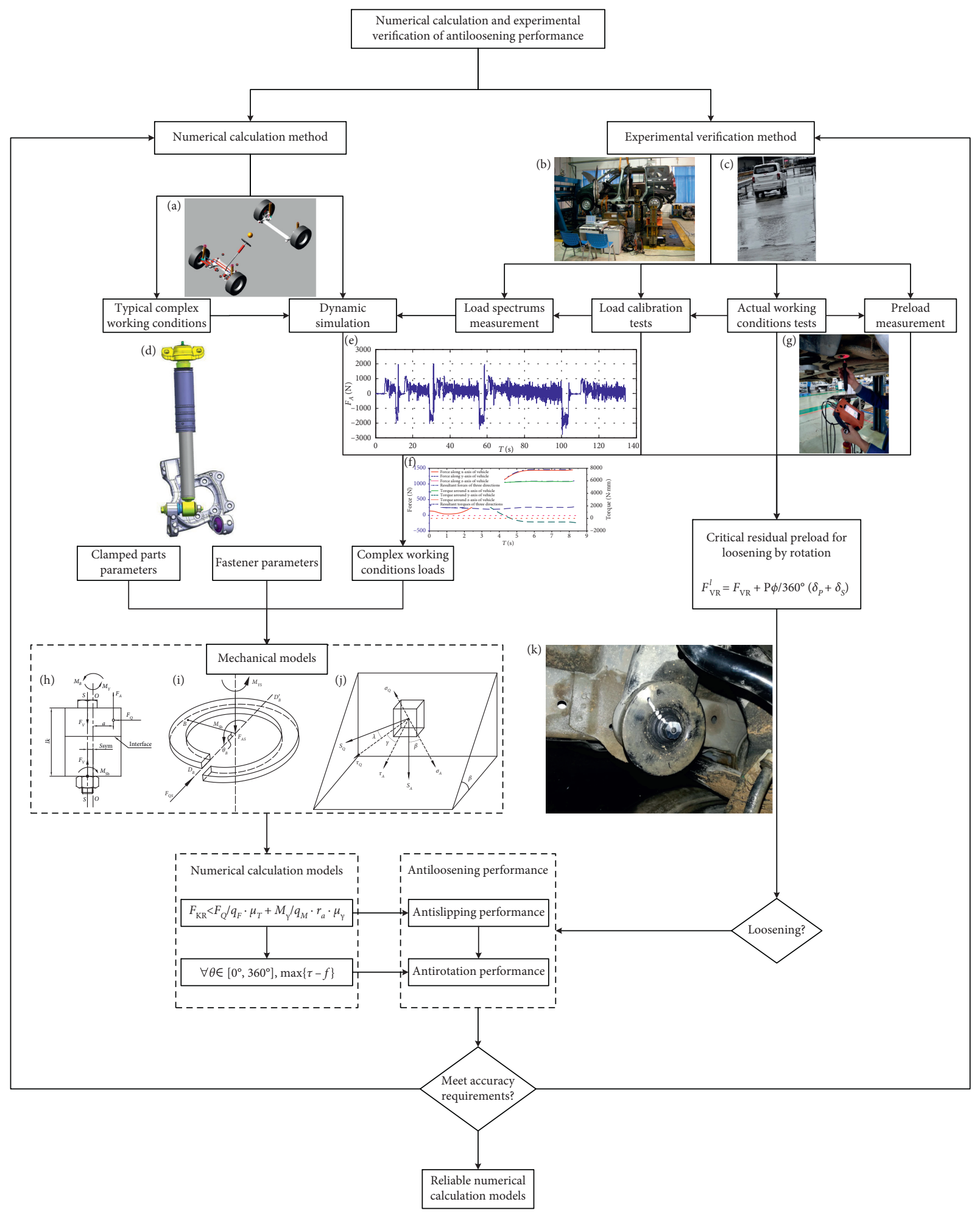

FIGURE 1: Research and verification scheme for numerical calculation model of antiloosening performance under complex working conditions loading. (a) Dynamic simulation model. (b) Load calibration tests. (c) Tests under actual working conditions. (d) Clamped parts and fastener model. (e) Load data obtained by load calibration tests and tests under actual working conditions. (f) Load data obtained by dynamics simulation. (g) Preload measurement by the ultrasonic measuring system. (h) The mechanical model of SJSs under complex working loads. (i) The mechanical model of the bolt thread surface under complex working loads. (j) The microarea mechanical model at point $B$ on the thread. (k) Loosening state of the SJS during the tests under actual working conditions. 
and the numerical calculation model was derived. Considering the stress state of the thread surface, the mechanical models of the thread surface (Figure 1(i)) and the thread microarea (Figure 1(j)) were established to investigate antiloosening performance. (3) The measuring scheme of the critical residual preload for loosening by rotation under actual working conditions was constructed to verify the numerical calculation model (Figures $1(\mathrm{~g})$ and $1(\mathrm{k})$ ).

Based on the abovementioned scheme, the numerical calculation model of the interaction amongst the structural parameters, complex working loads, and loosening by rotation was established to expand the application scope of existing models and predict the performance and failure of SJs. Subsequently, a new experimental scheme (including the load extraction under complex working conditions, measurement of critical residual preload, and two practical engineering cases) was used to confirm the reliability and accuracy of the numerical calculation model. Finally, based on the model, the effects of transverse load, axial load, bending moment, torque about the bolt axis, clamping eccentricity, loading eccentricity, and coefficient of friction in the thread and at the interface were analyzed in terms of antiloosening performance.

\section{Mechanical Models}

By considering the slip state of the interface and the local stress state of the thread, mechanical models were established to investigate the numerical calculation model of the interaction amongst the structural parameters, complex working loads, and antiloosening performance. This study divided the loosening process of the SJSs into the following three stages, based on previous studies [12-14], which divided the loosening process into two stages.

Stage 1 (plastic deformation of materials). The attenuation of the preload is mainly caused by the plastic deformation and expansion of the material. If the preload can ensure that relative slip does not occur at the interface of clamped parts, the bolt, nut, and thread surface will not be affected by external transverse loads and will not loosen by rotation.

Stage 2 (relative slip of clamped parts). With the continuous attenuation of the preload in the first stage, the interface of the clamped parts relatively slips owing to the decrease of the friction force, and the forces at the thread surface and bearing surface change. The bolt's bending deformation can absorb the transverse load, which is small, and the bearing surface and thread surface do not slip and rotate owing to the frictional resistance. Therefore, the bolt and nut do not loosen by rotation.

Stage 3 (loosening by rotation of the bolt/nut). With further preload attenuation, the relative slip and rotation of the bolt and nut occur when the loads on the structure reach a critical value, and the forces exerted on the bearing surface and thread surface are greater than the friction resistance.
In the first and second stages, the preload attenuation is mainly caused by the plastic deformation of the material, and the decrease is slow. In the third stage, the preload rapidly decreases, which results in loosening failure. Therefore, it is necessary to ensure that the SJSs are in the first two stages throughout the service life and avoid them entering the third stage. When the SJSs must satisfy the requirements of stability, sealing, and corrosion resistance, they must be in the first stage and the relative slip of the interface is not allowed. The numerical calculation model for the loosening process of the SJSs under complex working conditions loading was investigated as described below.

Owing to the elastic characteristics of the clamped parts and the bolt/nut, the axial load and bending moment on the clamped parts are proportionally transmitted to the bolt. Simultaneously, the plastic deformation of the bolt and clamped parts reduce the clamp load on the interface. When calculating the residual clamp load $F_{\mathrm{KR}}$ and safety margin against the interface slipping $S_{G}$, VDI2230 [6] only considers the axial load and loss of preload caused by plastic deformation; it does not consider the influence of the bending moment $M_{B}$ on the clamping load of the interface under eccentric clamping and eccentric loading, which affects the accuracy of the interface's antislipping safety verification. Considering the abovementioned factors, the mechanical model was established (Figure 2), and the residual clamp load in the clamping area was calculated using the following equation:

$$
F_{\mathrm{KR}}=F_{M}-\left(1-\Phi_{\mathrm{en}}^{*} F_{A}\right)+\left(\frac{\Phi_{m}^{*}}{s_{\mathrm{sym}}}\right) M_{B}-F_{Z},
$$

where $F_{V}$ is the preload (general); $F_{M}$ is the assembly preload; $\Phi_{\text {en }}^{*}$ is the load factor for the eccentric clamping and eccentric loading; $F_{A}$ is the axial load; $\Phi_{m}^{*}$ is the load factor for the moment loading and eccentric clamping; $s_{\text {sym }}$ is the clamping eccentricity, whose sign rule is given in VDI-2230 [6]; $M_{B}$ is the bending moment; and $F_{Z}$ is the loss of preload caused by plastic deformation, which can be calculated according to VDI-2230 [6].

Thus, the interface's antislipping verification criterion is established. First, the residual clamp load in the clamping area $F_{\mathrm{KR}}$ is calculated under complex working conditions. Second, the clamp load $\left(F_{Q} /\left(q_{F} \cdot \mu_{T}\right)\right)+\left(M_{Y} /\left(q_{M} \cdot r_{a} \cdot \mu_{T}\right)\right)$ is calculated to transfer the transverse load $F_{Q}$ and the torque about the bolt axis $M_{Y}$. Third, the residual clamp load is compared with the required clamp load. In particular, if the residual clamp load is less than the required clamp load, the interface is assessed as slip; otherwise, it is assessed as no slip, as expressed in the following equation:

$$
F_{\mathrm{KR}}>\frac{F_{Q}}{q_{F} \cdot \mu_{T}}+\frac{M_{Y}}{q_{M} \cdot r_{a} \cdot \mu_{T}},
$$

where $F_{Q}$ is the transverse load; $M_{Y}$ is the torque about the bolt axis; $q_{F}$ and $q_{M}$ denote the number of 


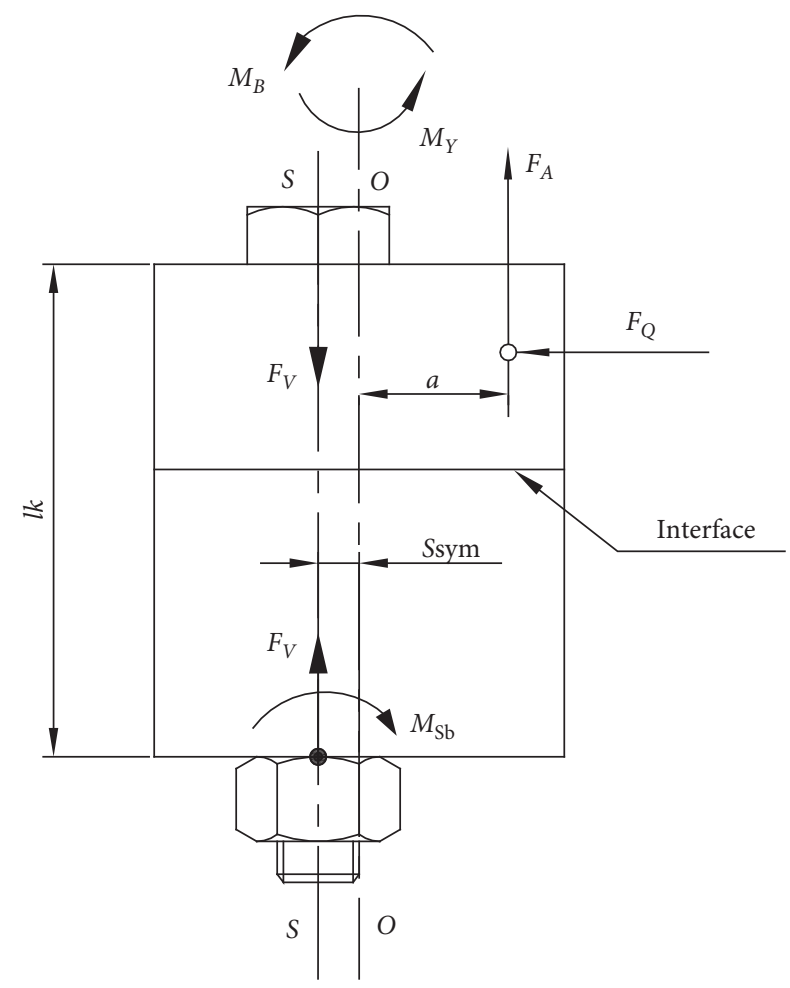

Figure 2: Mechanical model of SJSs under complex working conditions loading.

force-transmitting and torque-transmitting interfaces, respectively; $\mu_{T}$ is the coefficient of friction at the interface; and $r_{a}$ is the friction radius at the clamped parts under the action of $M_{Y}$.

The critical condition for the loosening by rotation of the bolts/nuts was investigated based on the interface's antislipping verification criterion. When the interface is assessed to slip according to the verification criteria, that is, when equation (2) is not verified, the axial load $F_{A S}$ of the bolt bears, which is the proportional transmission of the axial load $F_{A}$, transverse load $F_{Q S}$, and torsion about the bolt axis $M_{Y S}$, all of which result from the transverse load $F_{Q}$ and torque about the bolt axis $M_{Y}$ overcoming the friction, can be calculated as expressed by the following equations:

$$
\begin{gathered}
F_{A S}=\Phi_{\mathrm{en}}^{*} \cdot F_{A}, \\
F_{\mathrm{QS}}=F_{\mathrm{Q}}+\frac{M_{Y}}{r_{a}}-F_{\mathrm{KR}} \cdot \mu_{T} \cdot q, \\
M_{Y S}=M_{Y}-\left(F_{\mathrm{KR}} \cdot \mu_{T} \cdot q-F_{\mathrm{Q}}\right) \cdot r_{a} .
\end{gathered}
$$

If the interface does not slip, the bending moment $M_{\mathrm{Sb}}$ acting on the bolt can be calculated according to VDI-2230 [6], as expressed by equation (6). By considering that the bolt bears the additional bending moment $F_{Q S} \cdot l_{K}$ caused by the transverse load $F_{Q S}$ when the interface slips, the bending moment acting on the bolt can be derived as expressed by equation (7):

$$
\begin{aligned}
M_{\mathrm{Sb}}= & \frac{\beta_{P}}{\beta_{S}}\left[F_{A} \cdot a-\Phi_{\mathrm{en}}^{*} F_{A} \cdot s_{\mathrm{sym}}+M_{B}\left(1-\frac{s_{\mathrm{sym}}}{\left|s_{\mathrm{sym}}\right|} \Phi_{m}^{*}\right)\right] \\
M_{\mathrm{Sb}}= & F_{\mathrm{QS}} \cdot l_{K}+\frac{\beta_{P}}{\beta_{S}}\left[F_{A} \cdot a-\Phi_{\mathrm{en}}^{*} \cdot F_{A} \cdot s_{\mathrm{sym}}\right. \\
& \left.+M_{B}\left(1-\frac{s_{\mathrm{sym}}}{\left|s_{\mathrm{sym}}\right|} \Phi_{m}^{*}\right)-F_{\mathrm{QS}} \cdot l_{K}\right] \\
= & F_{\mathrm{QS}} \cdot l_{K}\left(1-\frac{\beta_{P}}{\beta_{S}}\right)+\frac{\beta_{P}}{\beta_{S}}\left[F_{A} \cdot a-\Phi_{\mathrm{en}}^{*} F_{A} \cdot s_{\mathrm{sym}}\right. \\
& \left.+M_{B}\left(1-\frac{s_{\mathrm{sym}}}{\left|s_{\mathrm{sym}}\right|} \Phi_{m}^{*}\right)\right]
\end{aligned}
$$

where $l_{K}$ is the clamping length; $\beta_{P}$ is the elastic bending resilience of the clamped parts; and $\beta_{S}$ is the elastic bending resilience of the bolt.

Based on [24], a mechanical model of the bolt thread surface under complex working loads is established, as shown in Figure 3. $D D^{\prime}$ is a line passing through the center and along the same direction as the transverse load. The different positions of the circumferential direction of the thread surface are represented by the angle $\theta$ between the radius of the cross-cutting circle and line $D D^{\prime}$; the range of $\theta$ is $\left[0^{\circ}, 360^{\circ}\right]$. Additionally, $\theta=0^{\circ}$ corresponds to the location closest to the action point of the transverse load, and $\theta=180^{\circ}$ corresponds to the location farthest from the action point of the transverse load. As the radial dimension of the thread surface is small, it is assumed that the stress distribution along the radial direction is uniform. A pair of thread pairs is equivalent to the mass block/bevel model, and the bevel angle is equal to the lead angle of the thread. Figure 4 [24] can be used to analyze the forces acting on the microarea at point $B$ on the thread, wherein the square represents the bolt thread, and the bevel represents the nut thread.

Moreover, $S_{\mathrm{Q} 1}$ and $S_{\mathrm{Q} 2}$ are the transverse stresses generated by the transverse loads and torque about the bolt axis on the microarea of the bolt thread; $S_{Q}$ and $S_{A}$ are the transverse and axial combined stresses on the microarea of the bolt thread, as calculated by the following equations:

$$
\begin{gathered}
S_{\mathrm{Q} 1}=\frac{F_{\mathrm{QS}}}{A_{\text {slip }}}, \\
S_{\mathrm{Q} 2}=\frac{2 M_{Y S}}{d_{2} \cdot A_{\text {slip }}}, \\
S_{\mathrm{Q}}=\sqrt{S_{\mathrm{Q} 1}^{2}+S_{\mathrm{Q} 2}^{2}+2 S_{\mathrm{Q} 1} \cdot S_{\mathrm{Q} 2} \cdot \cos \alpha} \\
S_{A}=\frac{F_{A S}}{A_{\text {slip }}}-\frac{M_{\mathrm{sb}} \cdot d_{2} \cdot \cos \theta}{2 I_{z}} \\
A_{\text {slip }}=\frac{\pi \cdot\left(d^{2}-d_{1}^{2}\right)}{4},
\end{gathered}
$$




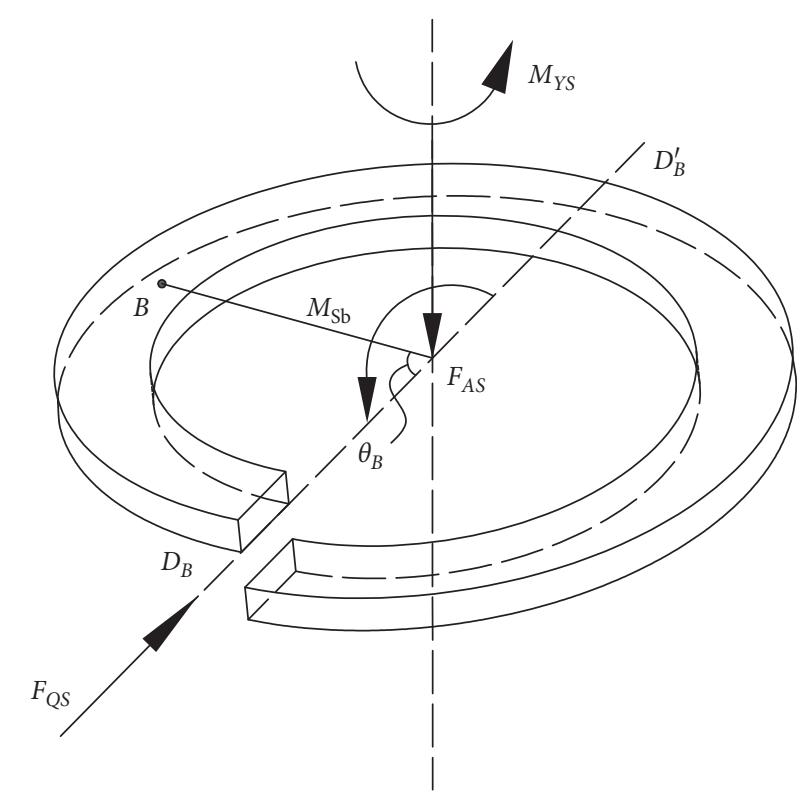

FIgURE 3: Mechanical model of bolt thread surface under complex working loads.

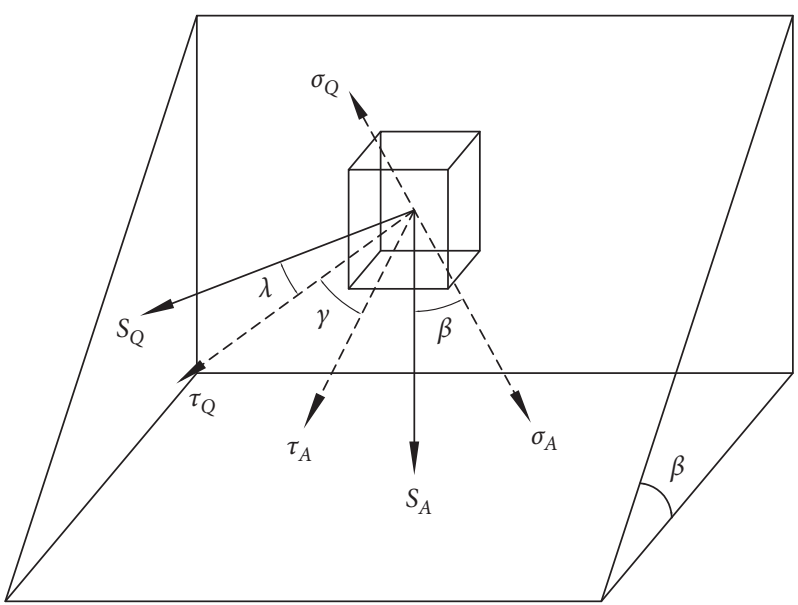

Figure 4: Microarea mechanical model at point $B$ on the thread.

where $A_{\text {slip }}$ is the contact area of a single-thread surface; $d$, $d_{1}$, and $d_{2}$ are the outside diameter, minor diameter, and pitch diameter of the thread, respectively; $I_{z}$ is the moment of inertia of the lateral section of the bolt; and $\alpha$ is the angle between the two transverse stresses, and it is deduced to be related to $\theta$, as expressed in the following equation:

$$
\cos \alpha=-\sin \theta .
$$

Moreover, $\sigma_{Q}$ and $\tau_{Q}$ are the normal and tangential stresses generated by $S_{Q}$ on the thread surface, as calculated by equation (13); $\sigma_{A}$ and $\tau_{A}$ are the normal and tangential stresses generated by $S_{A}$ on the thread surface, as calculated by equation (14); $\lambda$ is the angle between the transverse stress and its projection line on the thread surface; $\beta$ is the angle between the axial stress and its normal line on the thread surface, whose value is equal to the lead angle; $\gamma$ is the angle between $\tau_{Q}$ and $\tau_{A}$ :

$$
\begin{gathered}
\sigma_{Q}=S_{Q} \cdot \sin \lambda, \\
\tau_{Q}=S_{Q} \cdot \cos \lambda, \\
\sigma_{A}=S_{A} \cdot \cos \lambda, \\
\tau_{A}=S_{A} \cdot \sin \lambda .
\end{gathered}
$$

The angle $\lambda$ is related to $\beta$ and $\theta$, and the angle $\gamma$ is related to $\theta$ [35], as expressed in the following equations:

$$
\begin{gathered}
\sin \lambda=\sin \beta \cdot \sin \theta, \\
\cos \gamma= \begin{cases}\sin ^{2} \theta, & \theta \in\left[0^{\circ}, 180^{\circ}\right], \\
-\sin ^{2} \theta, & \theta \in\left(180^{\circ}, 360^{\circ}\right] .\end{cases}
\end{gathered}
$$

The tangential combined stress $\tau$ and friction stress $f$ on the thread surface are calculated using the following equations: 


$$
\begin{gathered}
\tau=\sqrt{\tau_{A}^{2}+\tau_{Q}^{2}+2 \tau_{A} \tau_{Q} \cos \gamma} \\
= \begin{cases}\sqrt{\tau_{A}^{2}+\tau_{Q}^{2}+2 \tau_{A} \tau_{Q} \sin ^{2} \theta}, & \theta \in\left[0^{\circ}, 180^{\circ}\right], \\
\sqrt{\tau_{A}^{2}+\tau_{Q}^{2}-2 \tau_{A} \tau_{Q} \sin ^{2} \theta}, & \theta \in\left(180^{\circ}, 360^{\circ}\right],\end{cases} \\
f= \begin{cases}\left(\sigma_{A}-\sigma_{Q}\right) \cdot \mu_{G}, & \theta \in\left[0^{\circ}, 180^{\circ}\right], \\
\left(\sigma_{A}+\sigma_{Q}\right) \cdot \mu_{G}, & \theta \in\left(180^{\circ}, 360^{\circ}\right] .\end{cases}
\end{gathered}
$$

According to previous studies [15, 16], in the process of bolt/nut loosening by rotation, the thread surface rotates first, drives the rotation of the bearing surface of the bolt head, and the local slip of the thread surface causes loosening by rotation. Therefore, the condition for the loosening by rotation not occurring is that the tangential combined stress at any position on the thread surface is less than or equal to the friction stress, as expressed by the following equation:

$$
\tau-f= \begin{cases}\sqrt{\tau_{A}^{2}+\tau_{Q}^{2}+2 \tau_{A} \tau_{Q} \sin ^{2} \theta}-\left(\sigma_{A}-\sigma_{Q}\right) \cdot \mu_{G} \leq 0, & \forall \theta \in\left[0^{\circ}, 180^{\circ}\right], \\ \sqrt{\tau_{A}^{2}+\tau_{Q}^{2}-2 \tau_{A} \tau_{Q} \sin ^{2} \theta}-\left(\sigma_{A}+\sigma_{Q}\right) \cdot \mu_{G} \leq 0, & \forall \theta \in\left(180^{\circ}, 360^{\circ}\right] .\end{cases}
$$

When the working load and structural parameters of an SJS are determined, the critical residual preloads for the loosening by rotation $F_{\mathrm{VR}}^{l}$ (the critical value of the residual preload in the case of loosening by rotation) can be obtained using the abovementioned equations. In other words, $F_{\mathrm{VR}}^{l}$ can be obtained when $\max \{\tau-f\}=0$, $\forall \theta \in\left[0^{\circ}, 360^{\circ}\right]$.

\section{Verification of Numerical Calculation Model of Antiloosening Performance}

Considering the SJSs of a certain vehicle as examples, the accuracy of the numerical calculation of the antiloosening performance model was verified by conducting a vehicle road test to measure the critical residual preload of the loosening by rotation.

3.1. Load Extraction under Complex Working Conditions. Accurate load extraction was achieved under complex working conditions by combining a load calibration test and vehicle road test and dynamics simulation. The testing systems and procedures are listed in Table 1.

The dynamic model comprises the body, front and rear suspension, steering system, power assembly, and tire and braking system and includes 46 rigid bodies in total. The number and types of kinematic constraints are as follows: 14 ball hinges, 10 rotating hinges, 12 constant speed hinges, 6 moving hinges, 3 cylindrical hinges, 2 hook hinges, and 1 gear rack hinge. The number and types of force elements are 44 rubber bushes, 4 suspension springs, 4 dampers, 2 torsion springs in the front and rear stabilizers, 4 tire force elements, and 4 braking forces.

3.2. Measurement of Critical Residual Preload of Loosening by Rotation. The procedures for measuring the critical residual preload of loosening by rotation are presented in Table 2.

$F_{\mathrm{VR}}^{l}$ is calculated as follows:

$$
F_{\mathrm{VR}}^{l}=F_{\mathrm{VR}}+\frac{P \varphi}{360^{\circ}\left(\delta_{P}+\delta_{S}\right)},
$$

where $P$ is the pitch; $\delta_{P}$ is the elastic resilience of the clamped parts; and $\delta_{S}$ is the elastic resilience of bolts.

3.3. Application Case for Verification of Numerical Calculation Model. Two sets of SJSs were selected (shock absorberbody SJS and crossarm-subframe SJS) to verify the numerical calculation model through the following key steps:

(1) Determining the SJS parameters, simulating the typical complex working conditions using a dynamic simulation model, and obtaining the ultimate working loads on the SJSs under the working condition of passing through a single-side pothole, as presented in Table 3.

(2) For the assembly preload $F_{M}$, assessing whether the bolt/nut will loosen by rotation. Calculating the loss of preload $F_{Z}$ according to VDI-2230 [6]; calculating the residual clamp load $F_{\mathrm{KR}}$, axial load $F_{A S}$, transverse load $F_{Q S}$, torsion about the bolt axis $M_{Y S}$, and bending moment $M_{\mathrm{Sb}}$ according to equations (2), (4)-(6), and (8); calculating $\max \{\tau-f\}, \forall \theta \in$ $\left[0^{\circ}, 360^{\circ}\right]$ according to equations (9)-(20); if $\max \{\tau-f\} \leq 0$, the bolt/nut will not loosen by rotation; if $\max \{\tau-f\}>0$, the bolt/nut will loosen by rotation. The calculation and assessment results are presented in Table 4.

(3) Based on the parameters and working loads listed in Table 3, calculating the critical residual preloads for the loosening by rotation $F_{\mathrm{VR}}^{l}$, that is, the solution of $F_{M}-F_{Z}$ is obtained when $\max \{\tau-f\}=0$, according to equations (2), (4)-(6), and (8)-(20). The critical residual preloads of the two SJS sets are $32,450 \mathrm{~N}$ and $19,865 \mathrm{~N}$, respectively.

The measurement data of the residual preload and rotation angle of the marking line are presented in Table 5. According to equation (1), the critical residual preloads for 
TABLE 1: Testing systems and load extraction procedures.

\begin{tabular}{|c|c|c|}
\hline Steps & Method & Example \\
\hline 1 & Strain gauges are pasted onto the clamped parts. & $\begin{array}{l}\text { Figure 5: strain gauges pasted onto the front suspension } \\
\text { (Figure 5(a)) and rod-coil spring rear axle (Figure 5(b)). }\end{array}$ \\
\hline 2 & $\begin{array}{l}\text { Exerting forces on the clamped parts, collecting the strain gauge } \\
\text { signals through the load calibration test, and determining the } \\
\text { relationship matrix between the strain signals and the exerted } \\
\text { forces. }\end{array}$ & $\begin{array}{l}\text { Figure 6: exerting a lateral force on the left rear wheel } \\
\text { (Figure 6(a)), a longitudinal force on the left front wheel } \\
\text { (Figure 6(b)), and a lateral force on the left front wheel } \\
\text { (Figure 6(c)). The test equipment and test method are describec } \\
\text { in [36]. }\end{array}$ \\
\hline 3 & $\begin{array}{l}\text { Collecting the dynamic strain signals of the clamped parts during } \\
\text { the vehicle road test; transforming the signals into load } \\
\text { spectrums using the relationship matrix. }\end{array}$ & $\begin{array}{l}\text { Figure 7: vehicle road test; Figure 8: vertical force spectrum } F_{A} \\
\text { and lateral force spectrum } F_{Q} \text { on left rear wheel under the } \\
\text { braking condition. }\end{array}$ \\
\hline
\end{tabular}

Calibrating the dynamics simulation model through the relationship matrix and load spectrums, simulating the typical

4 complex working conditions, outputting the loads acting on the SJSs corresponding to the coordinate system of the vehicle, and determining the ultimate working condition corresponding to
Figure 9: dynamics simulation model. Figure 10: working loads acting on the shock absorber-body SJS under the braking condition output from the dynamics simulation. the maximum load.

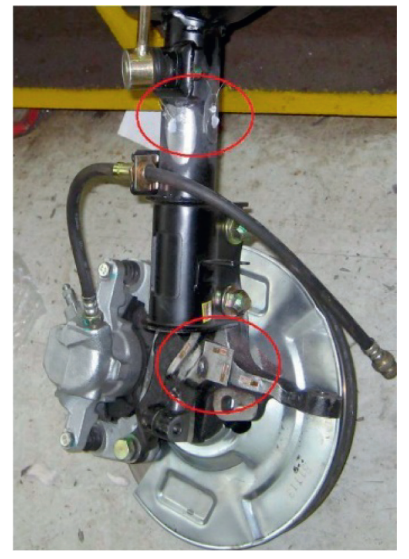

(a)

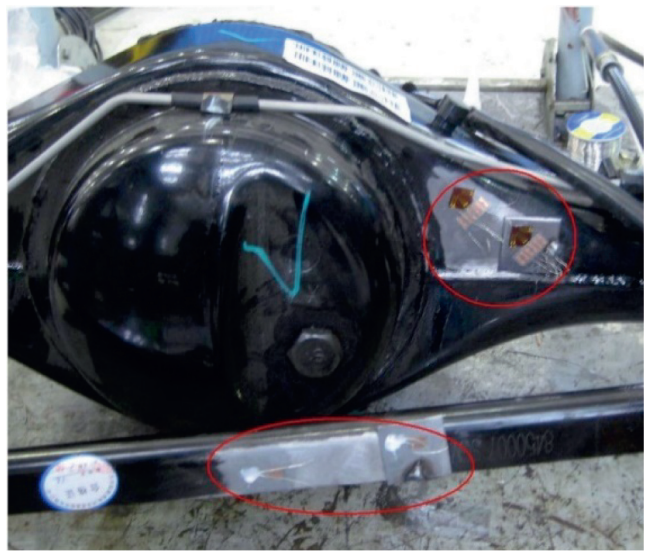

(b)

FIGURE 5: Strain gauge pasted on clamped parts: (a) strain gauge pasted on the front suspension; (b) strain gauge pasted on the rod-coil spring rear axle.

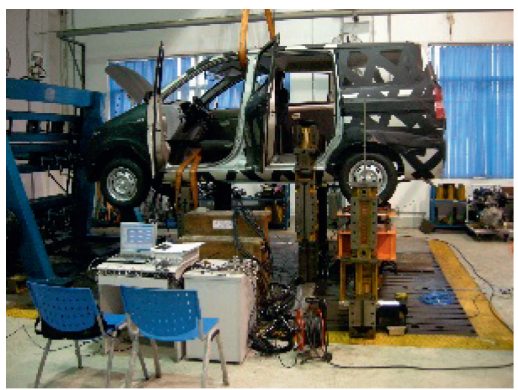

(a)

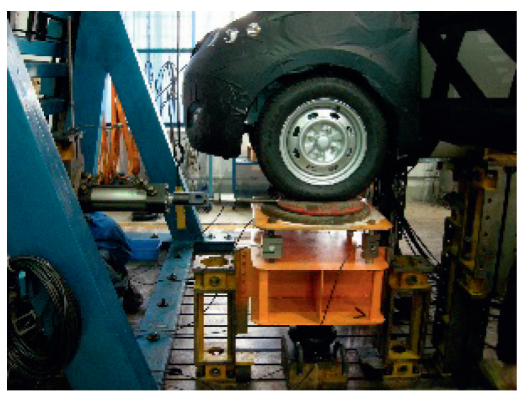

(b)

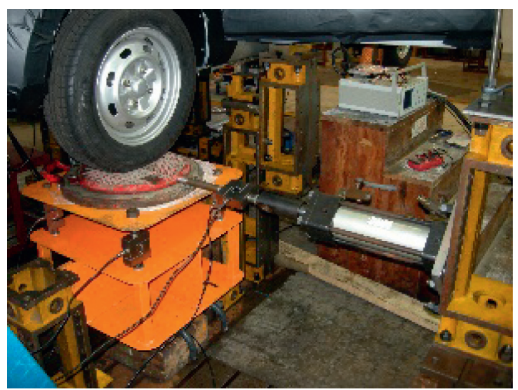

(c)

Figure 6: Load calibration tests: (a) lateral force on the left rear wheel; (b) longitudinal force on the left front wheel; (c) lateral force on the left front wheel.

the loosening by rotation of the two SJS sets are $30,740 \mathrm{~N}$ and $18,702 \mathrm{~N}$, respectively. The test and numerical results are presented in Table 6. The comparisons revealed that the test result values are slightly lower than the numerical result values, and the relative errors are $5.56 \%$ and $6.22 \%$, respectively. Based on an analysis of the loosening mechanism, in the numerical calculation, using the local slip of the thread surface as an antiloosening condition is a conservative 


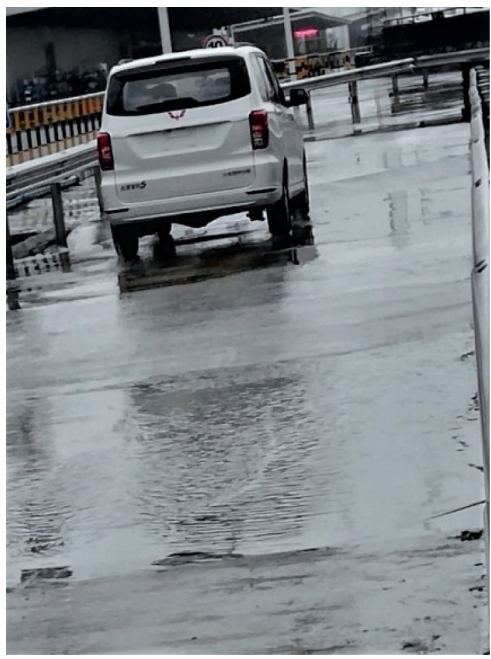

FIGURE 7: Vehicle road test.

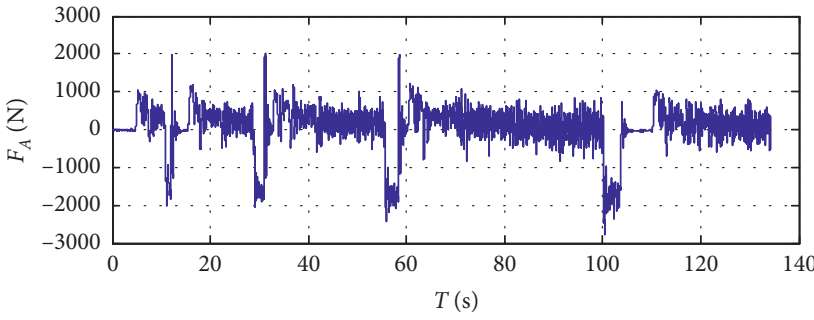

(a)

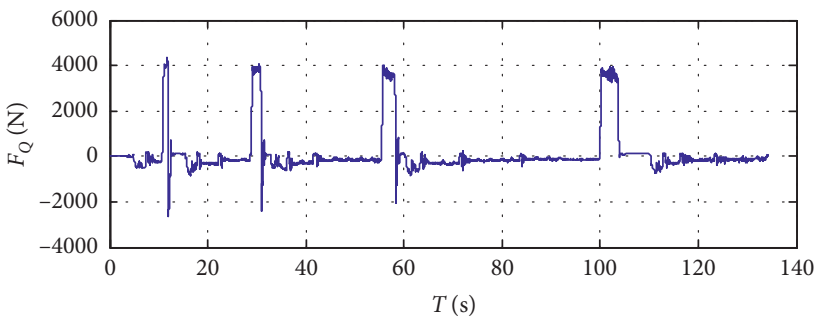

(b)

FIgURE 8: (a)Vertical force spectrum $F_{A}$ and (b) lateral force spectrum $F_{Q}$ for the left rear wheel under braking condition.

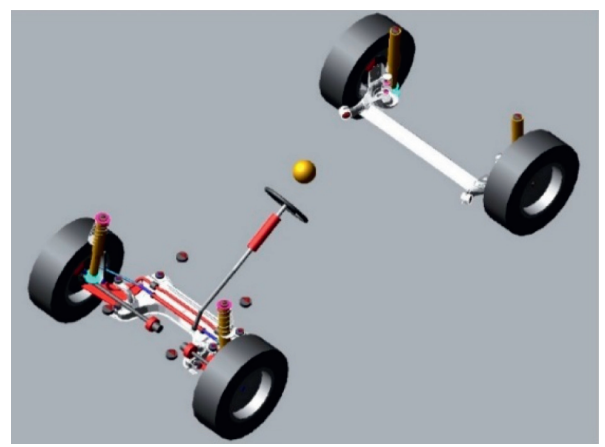

Figure 9: Dynamic simulation model.

approach that yields calculated values that are higher than the values obtained via testing. In engineering applications, a conservative design can ensure structural safety and reduce the likelihood of accidents.

\section{Investigation of Parameters Influencing Antiloosening Performance}

In the derivation described in the section "Mechanical Models," it was found that the antiloosening performance of the SJs is closely related to the working loads and structural parameters. Based on the numerical calculation model, the influences of transverse loading, axial loading, bending moment, torque about the bolt axis, clamping eccentricity, loading eccentricity, and coefficient of friction in the thread and at the interface on the antiloosening performance were analyzed. Based on the working loads and structural parameters of the shock absorber-body SJS in Table 1, the influence of each parameter on the critical residual preload of loosening by rotation was successively investigated by 


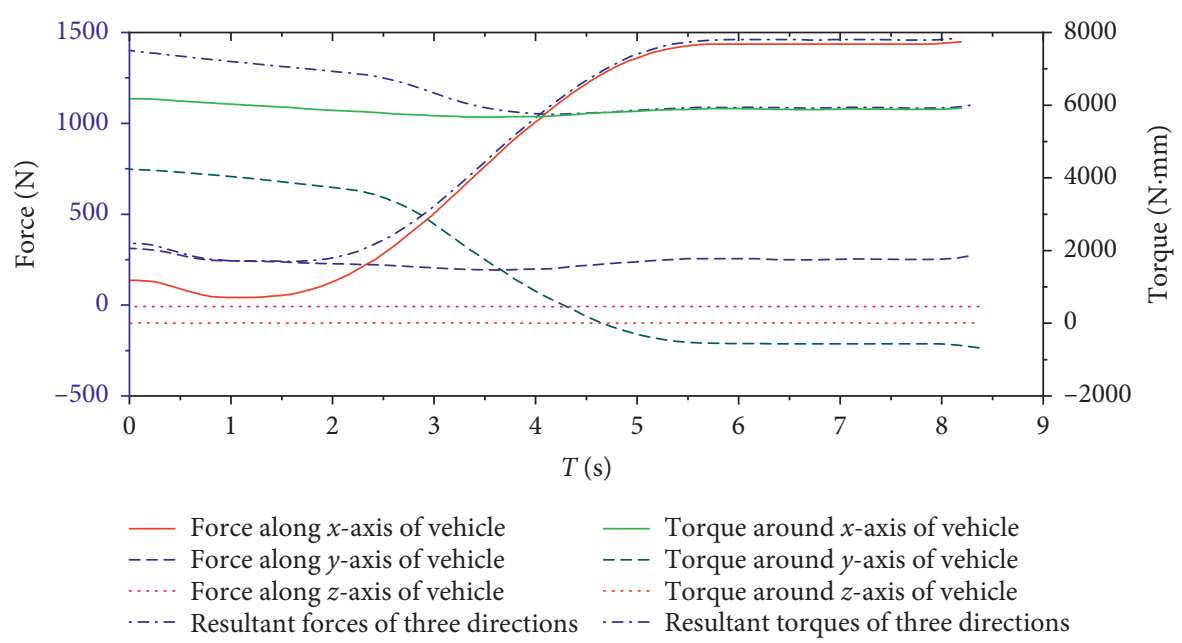

FIGURE 10: Working loads acting on shock absorber-body SJS under braking condition output from dynamics simulation.

TABle 2: Procedures for measuring critical residual preload of loosening by rotation.

\begin{tabular}{lr}
\hline Step & Procedure \\
\hline 1 & Before the actual working condition test, attaching the ultrasonic transducers to the bolt head (Figure 11). \\
2 & Calibrating the preloads on the bolts to ensure satisfactory accuracy for the preload measurement (Figure 12). \\
3 & For each test of one cycle under actual working conditions, monitoring the residual preload $F_{\mathrm{VR}}$ and rotation angle $\varphi$ of the marking \\
4 & line (Figure 13). \\
5 & If loosening by rotation occurs in the first monitoring, increasing and remonitoring the assembly preload $F_{M}$. \\
6 & $\begin{array}{r}\text { The residual preload } F_{\mathrm{VR}} \text { is obtained until loosening by rotation occurs after the first monitoring, and the calculation of the critical } \\
\text { residual preload of loosening by rotation } F_{\mathrm{VR}}^{l} \text { is calculated using equation }(20) .\end{array}$ \\
\hline
\end{tabular}

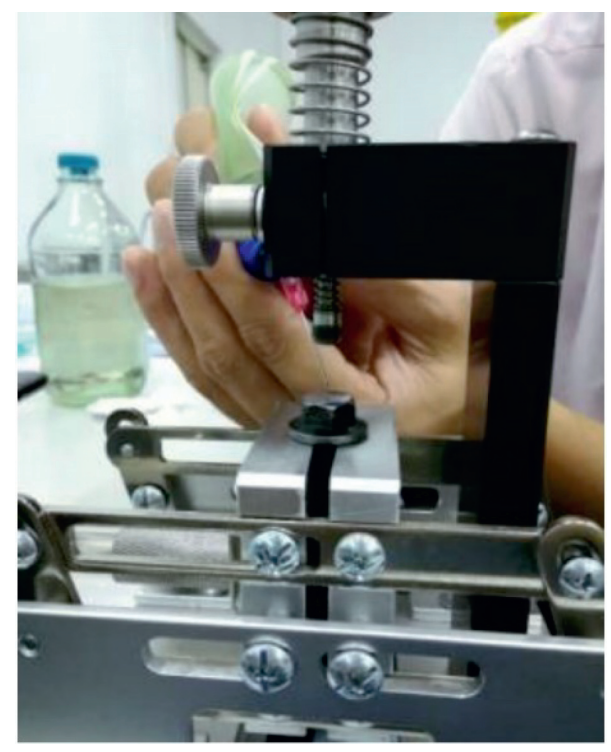

FIgURe 11: Pasting of ultrasonic transducers.

changing the value of one parameter within a certain range while keeping the other parameters unchanged, as shown in Figures 14-21. As the working loads and loading eccentricity increased, the critical residual preload of the loosening by rotation increased while the antiloosening performance decreased, as shown in Figures 14-18. As the friction coefficient at the interface and in the thread increased, the critical residual preloads for failure decreased and the 


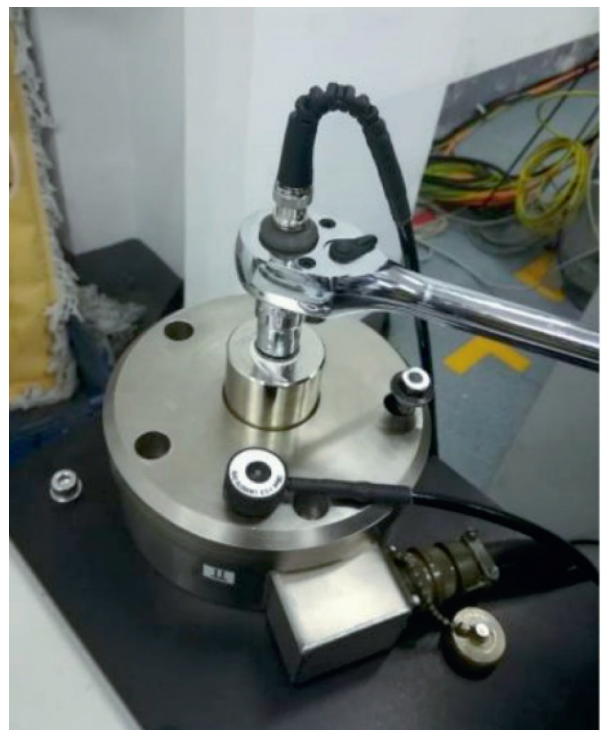

FIGURE 12: Calibration of bolt preload.

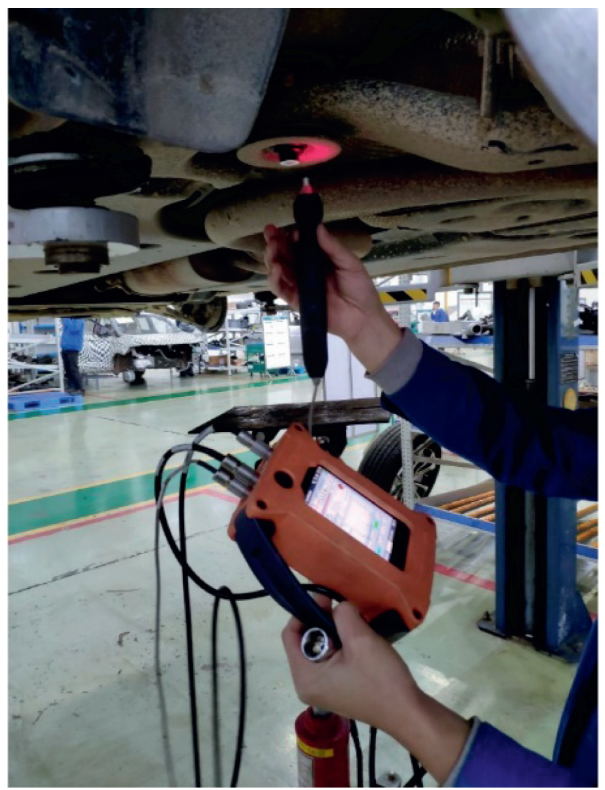

FIgURE 13: Preload measurement by the ultrasonic measuring system.

TABLE 3: SJS parameters and ultimate loads.

Parameter value

Outside diameter of thread, $d(\mathrm{~mm})$

Pitch of the thread, $P(\mathrm{~mm})$

10

1.25

2.48

Lead angle, $\beta\left({ }^{\circ}\right)$

Clamping length, $l_{k}(\mathrm{~mm})$

Elastic resilience of the bolt, $\delta_{S}\left(\mathrm{~mm} \cdot \mathrm{N}^{-1}\right)$

Elastic bending resilience of the bolt, $\beta_{s}\left(\mathrm{~mm} \cdot \mathrm{N}^{-1}\right)$

Coefficient of friction in the thread, $\mu_{G}$

Clamping eccentricity, $s_{\text {sym }}(\mathrm{mm})$

Elastic resilience of the clamped parts, $\delta_{P}\left(\mathrm{~mm} \cdot \mathrm{N}^{-1}\right)$

Elastic bending resilience of the clamped parts, $\beta_{p}\left(\mathrm{~mm} \cdot \mathrm{N}^{-1}\right)$

Friction radius at the clamped parts, $r_{a}(\mathrm{~mm})$

Coefficient of friction at the interface, $\mu_{T}$

Crossarm-subframe SJS

12

1.25

2.04

94

$4.69 \times 10^{-6}$

$1.49 \times 10^{-6}$

0.13

0

$1.92 \times 10^{-6}$

$1.54 \times 10^{-8}$

13.6

0.15 
TABLE 3: Continued.

Parameter name

Parameter value

Number of force-transmitting interfaces, $q_{F}$

Number of torque-transmitting interfaces, $q_{M}$

Transverse load, $F_{Q}(\mathrm{~N})$

Axial load, $F_{A}(\mathrm{~N})$

Bending moment, $M_{B}(\mathrm{~N} \cdot \mathrm{mm})$

Torque about the bolt axis, $M_{Y}(\mathrm{~N} \cdot \mathrm{mm})$

Loading eccentricity, $a(\mathrm{~mm})$

Load factor for concentric clamping and eccentric loading, $\Phi_{e n}$

Load factor for eccentric clamping and eccentric loading, $\Phi_{e n}^{*}$

Load factor for moment loading and concentric clamping, $\Phi_{m}$

Load factor for moment loading and eccentric clamping, $\Phi_{m}^{*}$ Shock absorber-body SJS

Crossarm-subframe SJS

TABLE 4: Calculation and assessment results for loosening by rotation.

Calculation/assessment result Shock absorber-body SIS Crossarm-subframe SJS

Assembly preload, $F_{M}(\mathrm{~N})$

Loss of preload, $F_{Z}(\mathrm{~N})$

32500

2311

24911

Residual clamp load, $F_{K R}(\mathrm{~N})$

30463

1161

Transverse load, $F_{Q S}(\mathrm{~N})$

Torsion about the bolt axis, $M_{Y S}(\mathrm{~N} \cdot \mathrm{mm})$

21469

35037

Bending moment, $M_{\mathrm{Sb}}$
$\max \{\tau-f\}\left(\mathrm{N} \cdot \mathrm{mm}^{-2}\right)$

93

Assessment results

Loosening

$\begin{array}{cc}1 & 3 \\ 1 & 3 \\ 5121 & 7028 \\ 5704 & 253 \\ 33116 & 72241 \\ 465 & 46948 \\ 17 & 13.6 \\ - & 1.09 \times 10^{-2} \\ 7.85 \times 10^{-2} & - \\ - & 1.03 \times 10^{-2} \\ 3.23 \times 10^{-3} & -\end{array}$

TABLE 5: Measured data for residual preload and rotation angle of marker line.

\begin{tabular}{lcc}
\hline Name of SJSs & Residual preload, $F_{\mathrm{PW}}(\mathrm{N})$ & Rotation angle of marker line, $\varphi\left(^{\circ}\right)$ \\
\hline Shock absorber-body SJS & 26800 & 5.4 \\
Crossarm-subframe SJS & 15500 & 6.1 \\
\hline
\end{tabular}

TABLe 6: Test and numerical results for critical residual preload for loosening by rotation.

\begin{tabular}{lccc}
\hline Name of SJSs & Test result $(\mathrm{N})$ & Numerical result $(\mathrm{N})$ & Relative error $(\%)$ \\
\hline Shock absorber-body SJS & 30740 & 32450 & 5.56 \\
Crossarm-subframe SJS & 18702 & 19865 & 6.22 \\
\hline
\end{tabular}

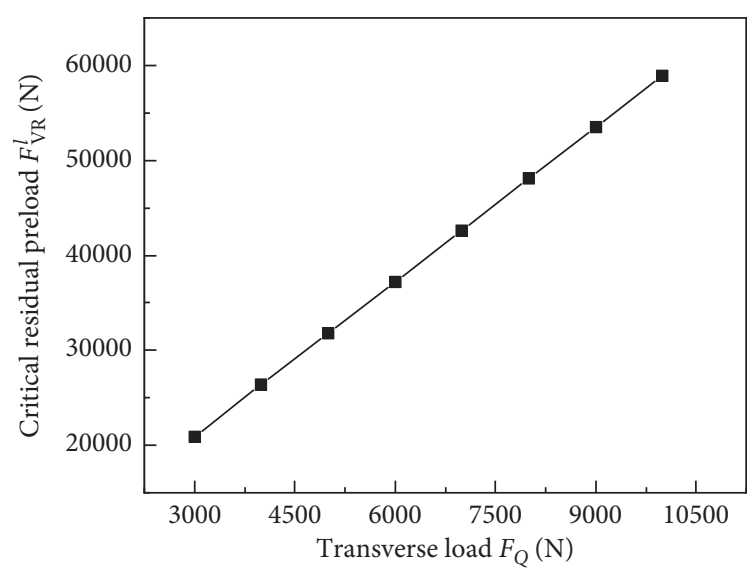

Figure 14: Relationship between transverse load and critical residual preload. 


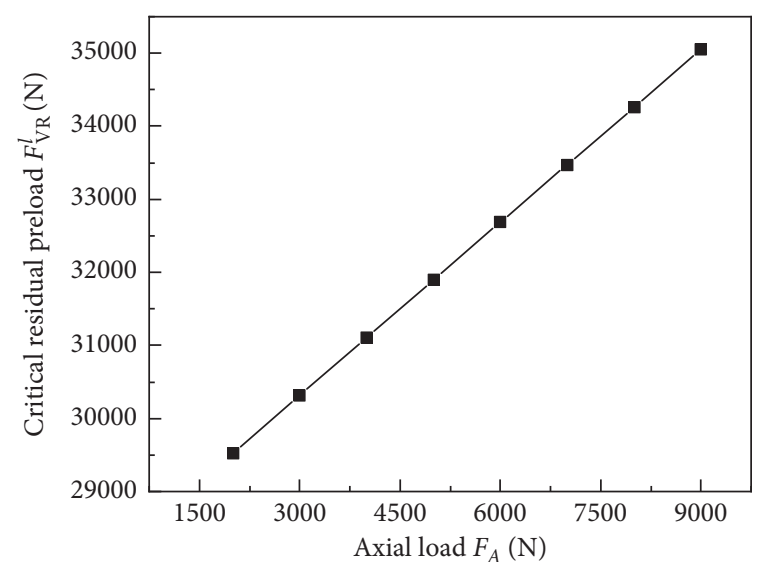

FIgURE 15: Relationship between axial load and critical residual preload.

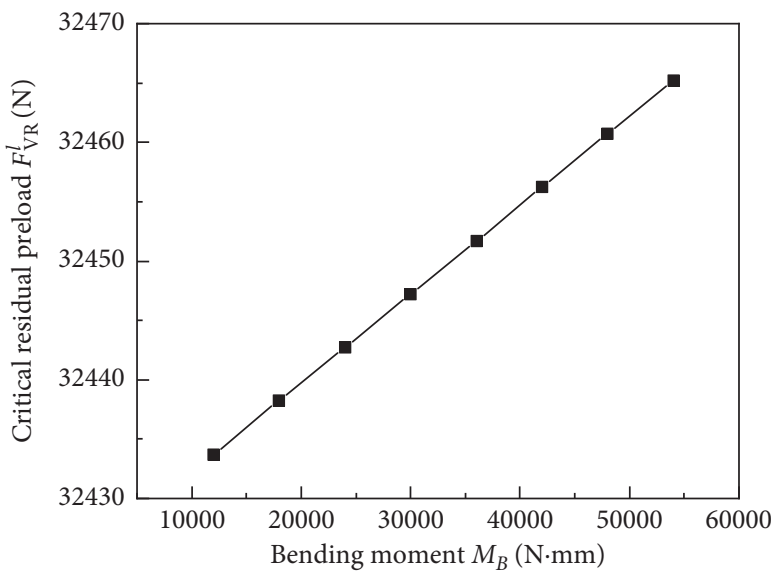

Figure 16: Relationship between bending moment and critical residual preload.

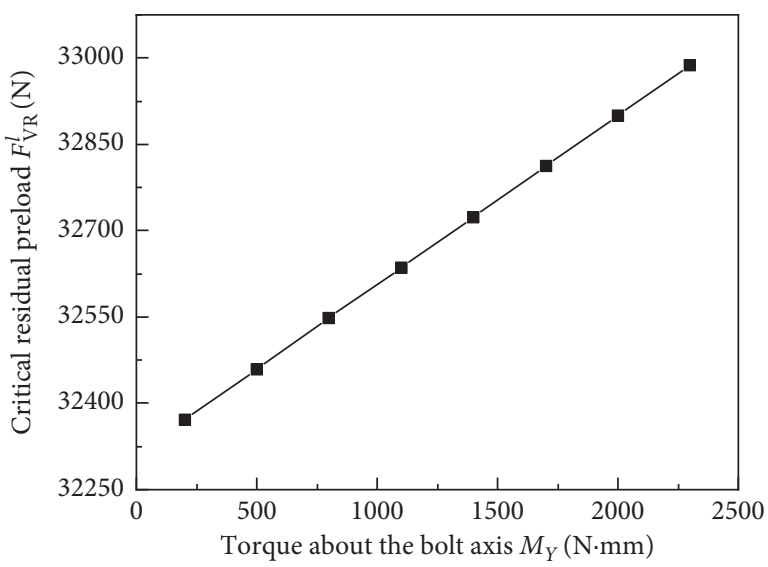

FIGURE 17: Relationship between torque about bolt axis and critical residual preload.

antiloosening performance improved, as shown in Figures 19 and 20. The influence of the clamping eccentricity on the critical residual preload of loosening by rotation depends

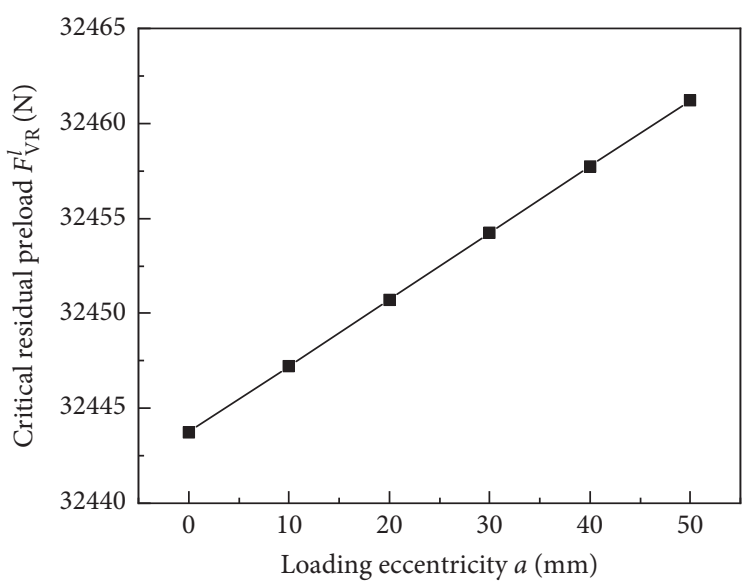

FIGURE 18: Relationship between loading eccentricity and critical residual preload.

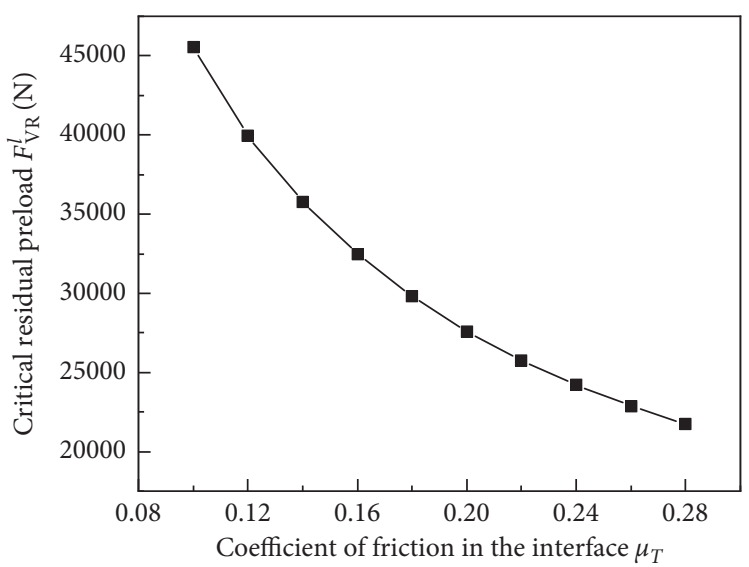

Figure 19: Relationship between coefficient of friction at interface and critical residual preload.

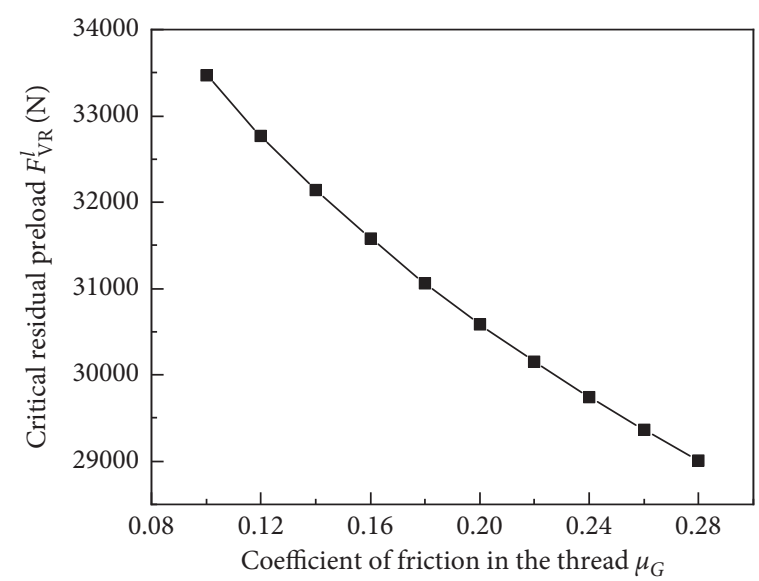

FIGURE 20: Relationship between coefficient of friction in the thread and critical residual preload.

on the distance $\left|a-s_{\text {sym }}\right|$ between the action line of the axial load and the bolt axis (Figure 5). As the clamping eccentricity increased, the distance $\left|a-s_{\text {sym }}\right|$ decreased, the critical 


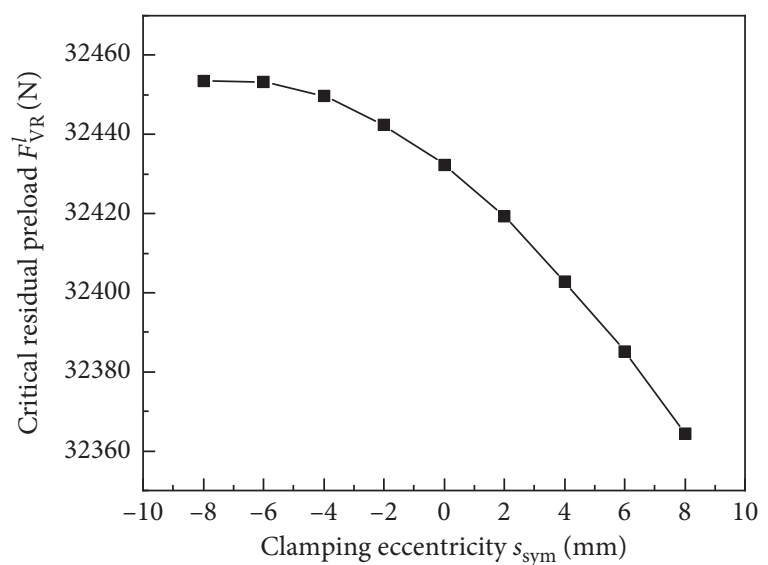

FIGURE 21: Relationship between clamping eccentricity and critical residual preload.

residual preload of loosening by rotation decreased, and the antiloosening performance improved, as shown in Figure 21. Notably, the antiloosening performance is sensitive to transverse loading, axial loading, torque about the bolt axis, and coefficient of friction in the thread and at the interface. Therefore, attention should be paid to the influences of these factors in the SJS design and failure prediction.

These influences of the preload, transverse load, and coefficient of friction in the thread on the antiloosening performance are consistent with those reported in the literature $[8,24]$. However, previous studies did not consider the effects of axial loading, bending moment, torque about the bolt axis, clamping eccentricity, loading eccentricity, and coefficient of friction at the interface. Therefore, existing numerical models $[8,24]$ are not suitable for calculating the critical residual preloads of the SJSs considered in this study and used in engineering practice.

In summary, the antiloosening performance of SJs is influenced by the working loads and structural parameters. Hence, by reasonably controlling the parameter values, the antiloosening performance can be improved and loosening failure can be avoided.

\section{Conclusions}

A numerical calculation model of antiloosening performance is proposed to obtain the exact complex working loads of SJSs. The accuracy and reliability of the proposed model were verified by testing. From the results obtained by this study, the following conclusions can be drawn:

(1) Load data were obtained through load calibration testing and load spectrum measurement tests under actual working conditions, and the dynamic simulation model was calibrated to ensure the satisfactory accuracy of the loads used as the data for numerically calculating and measuring the critical preload required for failure.

(2) By considering the complex working loads, slip state of the interface, stress state of the thread surface, influences of eccentric clamping and eccentric loading on the load, and the elastic resilience and load coefficient, mechanical SJ models were established, and the numerical calculation models of antiloosening performance were obtained. The proposed calculation method is simple and effective for use in engineering applications and can obtain the quantitative relationship and interaction amongst the structural parameters, load under complex working conditions, and antiloosening performance.

(3) Because it is difficult to validate the numerical calculation model's accuracy, the scheme for measuring the critical residual preload of loosening by rotation under actual working conditions was constructed, and the accuracy of the numerical calculation model was more efficiently verified in terms of time and cost. Because the maximum error between the test results and numerical results is $6.22 \%$ and the numerical results are conservative, the reliability and safety of the structure are ensured, and the accident risk is reduced.

(4) The numerical analysis results revealed that the transverse load, axial load, torque about the bolt axis, friction coefficient of the interface, and coefficient of friction in the thread greatly influence the antiloosening performance. The working loads, loading eccentricity, and distance between the action line of the axial load and bolt axis are negatively correlated with the antiloosening performance. The coefficients of friction in the thread and at the interface are positively correlated with the antiloosening performance. These results can be useful as guidelines in engineering practice.

As can be seen, the factors considered in the numerical calculation model are more comprehensive and suitable to practical engineering scenarios. The results obtained by this study expand the application scope of existing numerical calculation models of antiloosening performance and can accurately predict the antiloosening performance and loosening failure of SJs and provide technical support to improve the reliability and safety of SJs, particularly for key SJSs under complex working conditions loading. In future work, to further improve the prediction accuracy of antiloosening performance, the dynamic contact state and micromechanical behavior of the interface, thread surface, and bearing surface should be investigated by experiment or using the finite element method.

\section{Data Availability}

The data used to support the findings of this study are available from the corresponding author upon request.

\section{Conflicts of Interest}

The authors declare that there are no conflicts of interest regarding the publication of this paper. 


\section{Acknowledgments}

The authors acknowledge the financial support from the SAIC-GM-Wuling Automobile Co., Ltd.

\section{References}

[1] G. E. Ramey and R. C. Jenkins, "Experimental analysis of thread movement in bolted connections due to vibrations," Final Report NAS8-39131, National Aeronautics and Space Administration, Washington, DC, USA, 1995.

[2] J. N. Goodier and R. J. Sweeney, "Loosening by vibration of threaded fastening," Mechanical Engineering, vol. 67, pp. 798-802, 1945.

[3] S. K. Clark and J. J. Cook, "Vibratory loosening of bolts," in Proceedings of the SAE International, Warrendale, PA, USA, February 1966.

[4] G. H. Junker, "New criteria for self-loosening of fasteners under vibration," in Proceedings of the SAE International, pp. 314-335, Warrendale, PA, USA, February 1969.

[5] R. J. Finkelston, "How much shake can bolted joints take," Machine Design, vol. 44, pp. 122-125, 1972.

[6] Norm of the Association of German Engineers (VDI) 2230-1: 2014, Systematic Calculation of High Duty Bolted Joints: Joints with One Cylindrical Bolt, VDI Company Product and Process Design, Product Development and Mechatronics Department, Berlin, Germany, 2014.

[7] H. Gong and J. Liu, "Some factors affecting the loosening failure of bolted joints under vibration using finite element analysis," Proceedings of the Institution of Mechanical Engineers, Part C: Journal of Mechanical Engineering Science, vol. 232, no. 21, pp. 3942-3953, 2018.

[8] H. Gong, J. Liu, and X. Ding, "Study on the critical loosening condition toward a new design guideline for bolted joints," Proceedings of the Institution of Mechanical Engineers, Part C: Journal of Mechanical Engineering Science, vol. 233, no. 9, pp. 3302-3316, 2019.

[9] Z. Zhao, B. Liang, H. Liu, and Y. Li, "Simplified numerical model for high-strength bolted connections," Engineering Structures, vol. 164, pp. 119-127, 2018.

[10] L. Zhu, J. Hong, G. Yang, and X. Jiang, "Experimental study on initial loss of tension in bolted joints," Proceedings of the Institution of Mechanical Engineers, Part C: Journal of Mechanical Engineering Science, vol. 230, no. 10, pp. 1685-1696, 2016.

[11] L. Zhu, J. Hong, and X. Jiang, "On controlling preload and estimating anti-loosening performance in threaded fasteners based on accurate contact modeling," Tribology International, vol. 95, pp. 181-191, 2016.

[12] Y. Jiang, J. Chang, and C.-H. Lee, "An experimental study of the torque-tension relation for bolted joints," International Journal of Materials and Product Technology, vol. 16, no. 4-5, pp. 417-429, 2001.

[13] Y. Jiang, M. Zhang, and C.-H. Lee, "A study of early stage selfloosening of bolted joints," Journal of Mechanical Design, vol. 125, no. 3, pp. 518-526, 2003.

[14] Y. Jiang, M. Zhang, T.-W. Park, and C.-H. Lee, “An experimental study of self-loosening of bolted joints," Journal of Mechanical Design, vol. 126, no. 5, pp. 925-931, 2004.

[15] N. G. Pai and D. P. Hess, "Experimental study of loosening of threaded fasteners due to dynamic shear loads," Journal of Sound and Vibration, vol. 253, no. 3, pp. 585-602, 2002.
[16] W. Wang, H. Xu, Y. Ma et al., "Self-loosening mechanism of bolted joints under vibration," Journal of Vibration and Shock, vol. 33, no. 22, pp. 198-202, 2014.

[17] N. G. Pai and D. P. Hess, “Three dimensional finite element analysis of threaded fastener loosening due to dynamic shear load," Engineering Failure Analysis, vol. 9, no. 4, pp. 383-402, 2002.

[18] X. Jiang, Y. Zhu, J. Hong, X. Chen, and Y. Zhang, "Investigation into the loosening mechanism of bolt in curvic coupling subjected to transverse loading," Engineering Failure Analysis, vol. 32, pp. 360-373, 2013.

[19] G. Dinger, "Design of multi-bolted joints to prevent selfloosening failure," Proceedings of the Institution of Mechanical Engineers, Part C: Journal of Mechanical Engineering Science, vol. 230, no. 15, pp. 2564-2578, 2016.

[20] S. Izumi, M. Kimura, and S. Sakai, "Small loosening of boltnut fastener due to micro bearing-surface slip: a finite element method study," Journal of Solid Mechanics and Materials Engineering, vol. 1, no. 11, pp. 1374-1384, 2007.

[21] S. Izumi, T. Yokoyama, A. Iwasaki, and S. Sakai, "Three-dimensional finite element analysis of tightening and loosening mechanism of threaded fastener," Engineering Failure Analysis, vol. 12, no. 4, pp. 604-615, 2005.

[22] H. Gong, J. Liu, and X. Ding, "Thorough understanding on the mechanism of vibration-induced loosening of threaded fasteners based on modified Iwan model," Journal of Sound and Vibration, vol. 473, Article ID 115238, 2020.

[23] G. Dinger and C. Friedrich, "Avoiding self-loosening failure of bolted joints with numerical assessment of local contact state," Engineering Failure Analysis, vol. 18, no. 8, pp. 2188-2200, 2011.

[24] M. Zhang, L. Lu, M. Tang, and D. Zeng, "Research on numerical calculation method of critical Load for bolt loosening under transverse loading," Journal of Mechanical Engineering, vol. 54, no. 5, pp. 173-178, 2018.

[25] N. Nishimura, T. Hattori, M. Yamashita, and N. Hayakawa, "Self loosening behavior of metal thread joints under transverse cyclic loading," Key Engineering Materials, vol. 340-341, pp. 1467-1472, 2007.

[26] N. Nishimura, T. Hattori, M. Yamashita, and N. Hayakawa, "Sliding and loosening behavior of thread joints under transverse loading," Key Engineering Materials, vol. 353-358, pp. 894-897, 2007.

[27] Y. Chen, Q. Gao, and Z. Guan, "Self-loosening failure analysis of bolt joints under vibration considering the tightening process," Shock and Vibration, vol. 2017, Article ID 2038421, 15 pages, 2017.

[28] O. Ksentini, B. Combes, M. S. Abbes, A. Daidie, and M. Haddar, "Simplified model to study the dynamic behaviour of a bolted joint and its self loosening," Structural Engineering and Mechanics, vol. 55, no. 3, pp. 639-654, 2015.

[29] O. Ksentini, B. Combes, M. S. Abbes, A. Daidié, and M. Haddar, "Numerical study of self-loosening of a bolted assembly under transversal load," Mechanics \& Industry, vol. 17, no. 5, p. 507, 2016.

[30] X. Yang and S. Nassar, "Analytical and experimental investigation of self-loosening of preloaded cap screw fasteners," Journal of Vibration and Acoustics, vol. 133, no. 3, Article ID 031007, 8 pages, 2011.

[31] S. A. Nassar and B. A. Housari, "Effect of thread pitch and initial tension on the self-loosening of threaded fasteners," Journal of Pressure Vessel Technology, vol. 128, no. 4, pp. 590-598, 2005. 
[32] M. Zhang, Y. Jiang, and C.-H. Lee, "Finite element modeling of self-loosening of bolted joints," Journal of Mechanical Design, vol. 129, no. 2, pp. 218-226, 2007.

[33] V. Fort, A.-H. Bouzid, and M. Gratton, “Analytical modeling of self-loosening of bolted joints subjected to transverse loading," Journal of Pressure Vessel Technology, vol. 141, no. 3, Article ID 031205, 11 pages, 2019.

[34] T. Yokoyama, M. Olsson, S. Izumi, and S. Sakai, "Investigation into the self-loosening behavior of bolted joint subjected to rotational loading," Engineering Failure Analysis, vol. 23, pp. 35-43, 2012.

[35] W. Eccles, I. Sherrington, and R. D. Arnell, "Towards an understanding of the loosening characteristics of prevailing torque nuts," Proceedings of the Institution of Mechanical Engineers, Part C: Journal of Mechanical Engineering Science, vol. 224, no. 2, pp. 483-495, 2010.

[36] Y. Lai, H. Gao, X. Pang et al., "A suspension loading test bed," CN Patent 101620032A, Intellectual Property Press, Beijing, China, 2010. 